\title{
Laser interferometric analysis of glucose and sucrose diffusion in agarose gel
}

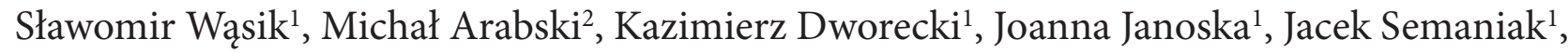 \\ Karol Szary ${ }^{1}$ and Andrzej Ślęzak ${ }^{3}$ \\ ${ }^{1}$ Institute of Physics, Jan Kochanowski University in Kielce, Świętokrzyska 15, 25-406 Kielce, Poland \\ ${ }^{2}$ Institute of Biology, Jan Kochanowski University in Kielce, Świętokrzyska 15, 25-406 Kielce, Poland \\ ${ }^{3}$ Department of Biophysics, Częstochowa University of Technology, Al. Armii Krajowej 36B, 42-200 Częstochowa, Poland
}

\begin{abstract}
The paper presents the investigation results of glucose and sucrose diffusion in agarose gel studied with laser interferometry method and the results of fluorescence analysis of the macroscopic gel structure. The diffusion kinetics of these substances released from aqueous solutions of a molar concentration of $0.05 \mathrm{M}$ into the agarose solutions of concentrations of $0.5 \%$ and $3 \%$ in two gravitational configurations of measuring system was analysed. In the first configuration the solute diffused according, whereas in the second one - opposite to the gravitational force. The diffusion was analysed in the time period between 120 and $2400 \mathrm{~s}$ with a time interval of $\Delta \mathrm{t}=120 \mathrm{~s}$. We observed that the convective instabilities were damped well by the agarose gel, which gives the possibility of the interferometric studies of the diffusive transport for other substances in different gravitational configurations of the system. The time characteristics of glucose and sucrose fluxes in both configurations of the system and the gravitational polarisation coefficient values were obtained. The substantial differences in fluxes of glucose and sucrose diffused according and opposite to the gravitational force were observed. Additionally, we observed the differences between the diffusive fluxes of these substances in both configurations in dependence on the gel solution concentration (which is associated with gel porosity dependent on its concentration) and the kind of diffused substance.
\end{abstract}

Key words: Laser interferometry - Diffusion - Convection - Substance flux - Agarose

\section{Introduction}

Polymers, which form the hydrogel structure due to their characteristics, are now widely used in many fields. They are used in the food and cosmetic, as well as the horticultural and agricultural production, act as subsoils of high water capacity. They also play significant role in medicine (Hoffman 2002) and laboratory analytics (Griess et al. 1989). Medicine uses the hydrogels for the manufacturing of drugs equipped with the system of controlled release of active substance (Brandl et al. 2010) and also for the production of hydrogel dressings. In the laboratory analytics the hydrogels are used

Correspondence to: Sławomir Wąsik, Institute of Physics, Jan Kochanowski University in Kielce, Świętokrzyska 15, 25-406 Kielce, Poland

E-mail: s.wasik@ujk.edu.pl as a substrate to immobilize the cells tested, and as a medium for bacterial colonies.

In recent times the hydrophilic gels provide new research possibilities here. Namely, due to the "anticonvection" properties of the gels, they make possible the studies of diffusive transport with suppression of convection instabilities. This allows one to directly determine the effect of gravity on the transport of substances in artificial as well as biological systems, which in the case of using aqueous solutions would be impossible. The influence of gravity on the substance transport can explain many effects, which are observed in biological systems under microgravity conditions (Schatz and Linke-Hommes 1989; Cogoli and Gründer 1991; Schatz et al. 1992). Lack of convection in microgravity favours the formation of diffusion boundary layers around the cells. These layers act as an additional resistance to permeation in series with the membrane resistance (Everitt and Haydon 
1969; Pedley and Fischbarg 1978, 1980; Pedley 1983; Barry and Diamond 1984; Berry and Verkman 1988; Zeuthen 1995; Pohl et al. 1997; Thomson and Dietschy 1997; Krylov et al. 2001). This additional resistance reduces solute and water fluxes through the cell membranes (Tosteson 1978; Potma et al. 2001). All perturbations in substance transport across cell membrane may result in gradients for nutrients, oxygen, and waste products (Cogoli and Gründer 1991; Schatz et al. 1992); therefore the cell metabolism is significantly affected. The effects at the cellular level cause the changes in the molecular organization, genetics, growth, cell division and differentiation, and morphological characteristics of single cells and the whole organism (changes in a human body during long spaceflights) (Cogoli and Gründer 1991; Sato et al. 1992; Cogoli 1993; Hughes-Fulford 1993; Claassen and Spooner 1994; Gasset et al. 1994; Cogoli and Cogoli-Greuter 1997; Tairbekov et al. 1997a, 1997b; Hatlan et al. 1998; Vico et al. 1998).

In the present paper, the experimental study of the effect of gravitational configuration on the substance transport in gel using laser interferometry is presented. The term of this effect requires the determination of substance fluxes in two different gravitational configurations of the system and the so-called gravitational polarization coefficient. The study of substance transport into and from the gels imitates permeation of substances into and from tissues (including human).

The method of laser interferometry is an optical method that uses interference of two laser beams, one of which passes through the investigated system and the second serves as a reference signal. The holographic interferometry and electron speckle pattern interferometry (ESPI) are accurate and precise tools to comprehensive study of the transport phenomena, quantitatively and qualitatively, in gels, liquids and membranes (Gustafsson et al. 1993; Westrin et al. 1994; Mattisson et al. 1996, 2000, 2001; Roger et al.2000; Axelsson and Marucci 2008). ESPI was used to determine of diffusion coefficients and partition coefficients of lysozyme, BSA (bovine serum albumin), and IgG in gels (Karlsson et al. 2002), to measure drug film permeability (Marucci et al. 2006) and to determine the effective diffusion coefficient of a solute in a permeable membrane (Marucci et al. 2007).

The method of laser interferometry, following modifications by the stabilization of the tested substance in the gel, was used by the authors in studies of the formation of colistin complexes with lipopolysaccharide (LPS) Proteus vulgaris O25 (Arabski 2007) and interactions of Proteus mirabilis S1959 LPS and its mutants R110 i R45 with chitosan and colistine in the presence of natural saponins (Arabski 2009a, 2009b).

In the present study, two-chamber system without the membrane was used as a model system. As a substances dif- fusing in the agarose gel, the sugars (glucose and sucrose) of different molar mass were used. One of the factors determining the use of agarose as a "anticonvection" medium is its great ability to gel at low concentrations.

The measurement results obtained using a laser interferometer indicate significant differences in the values of substance fluxes when the substance is transported to the gel against or according to the vector of the gravity force. The fluorescence analysis performed by using of confocal microscope shows the differences in macroscopic gel structure at different concentrations.

\section{Materials and Methods}

\section{Gel preparation}

In the present experiment we used agarose gel (made by SERVA Electrophoresis $\mathrm{GmbH}$, Germany) with a high degree of purity. This type of agarose is usually used in the preparation of nucleic acids as well as in the analytical techniques and have following features: gelling temperature $(1.5 \%) 34-39^{\circ} \mathrm{C}$, gel strength $(1.5 \%) \mathrm{min} .1700 \mathrm{~g} / \mathrm{cm}^{2}$, electroendosmosis (EEO) max. 0.13. Aqueous solutions of agarose were prepared at a controlled temperature. To $50 \mathrm{ml}$ of doubly deionized water $0.25 \mathrm{~g}$ or $1.5 \mathrm{~g}$ of agarose was added, next the solution was stirred with magnetic stirrer and heated at the same time to $100^{\circ} \mathrm{C}$. Then, the gel solution was cooled to $50^{\circ} \mathrm{C}$ and poured into a interferometric cuvette. Agarose gels were formed in $30 \mathrm{~min}$ at room temperature just before the experiment.

\section{Analysis of gel structure}

Agarose gel (5 ml) at concentration of $1 \%$ or $3 \%$ was heated $\left(100^{\circ} \mathrm{C}\right)$, cooled to $\sim 50^{\circ} \mathrm{C}$ and mixed with acridine orange at $50 \mu \mathrm{g} / \mathrm{ml}(5 \mathrm{ml})$, as the fluorescent dye. The mixtures were immediately placed on a slide $(50 \mu \mathrm{l})$ and covered with a cover glass. Fluorescence analysis of the agarose gel structure was performed by using of fluorescence inverted microscope Nikon Eclipse Ti with confocal attachment A1. The excitation and the emission wavelength were equal $487.9 \mathrm{~nm}$ and $525.0 \mathrm{~nm}$, respectively. Scan resolution of the gel sample X: 2048 Y: 2048 (mono 12 bit) and resolving power of the microscope was $0.31 \mu \mathrm{m} / \mathrm{px}$. From the investigated sample the plane with the highest values of fluorescence intensity was selected for the further analysis.

\section{Interferometric investigations}

The flux of substance $J_{\mathrm{s}}(t)$ which diffuses into the agarose gel after time $t$ were determined on the basis of concentration profile $C(x, t)$ according to: 


$$
J_{S}(t)=\frac{N(t)}{S t}=\frac{S \int_{0}^{\delta} C(x, t) d x}{S t}=\frac{\int_{0}^{\delta} C(x, t) d x}{t}
$$

where $C(x, t)$ denotes the substance concentration at a point located at a distance $x$ from the gel-solution interface, $\delta$ the concentration (diffusion) boundary layers (CBLs) thickness, and $S$ the surface of the gel-solution interface $(S=7$ $\times 10^{-5} \mathrm{~m}^{2}$ ). The concentration profiles and the thickness $\delta$ were obtained by using of interferometric method according to the equation:

$$
C(x, t)=C_{0}+a \frac{\lambda d(x, t)}{h f}
$$

where $C_{0}$ is the initial substance concentration, $h$ the thickness of the interferometric fringe, $\lambda$ the wavelength of the laser light $(632.8 \mathrm{~nm}), f$ the thickness of the solution layer in the measurement cuvette, $d(x, t)$ the deviation of the fringe from its straight line run at point $x$, and $a$ the proportionality constant between the concentration and the refraction index $\left(a=3.12 \times 10^{4} \mathrm{~mol} / \mathrm{m}^{3}\right.$ for the glucose gel solution and $a=1.82 \times 10^{4} \mathrm{~mol} / \mathrm{m}^{3}$ for the sucrose gel solution). The deviation $d(x, t)$ was determined on the basis of computer analysis of the run of interference fringes in the system under study. Detailed description of the method and diagram of interferometric measuring system was already presented in our previous work (Dworecki et al. 2006).

Gel system consisted of two cuvettes with optical glass having a high homogeneity with internal dimensions: height $70 \mathrm{~mm}$, width $10 \mathrm{~mm}$, thickness $7 \mathrm{~mm}$. In the case of using of hydrogels, it is not necessary to place a membrane between the substances. The agarose gel used in the experiment is hydrated and therefore does not swell. There is no shifting of phases boundary in the direction of aqueous solution which is placed in the second cuvette. This gel system was placed in the interferometric system, and the measurements were performed during $40 \mathrm{~min}$ with the time interval $\Delta \mathrm{t}=120 \mathrm{~s}$. It was found that after a period of $20 \mathrm{~min}$ the system reaches the stationary phase of diffusion process. For each substance two gravitational configurations of the system which are shown in Fig. 1 were tested. In the configuration I the substance diffuses in accordance with the gravity force, while in the configuration II - against this force. In the studies two agarose solutions of concentrations of $0.5 \%$ and $3 \%$ were used, while the concentration of aqueous solutions of glucose and sucrose were the same $-0.05 \mathrm{M}$. The analysis was carried out under isothermal conditions at $T=22 \pm 0.3^{\circ} \mathrm{C}$.
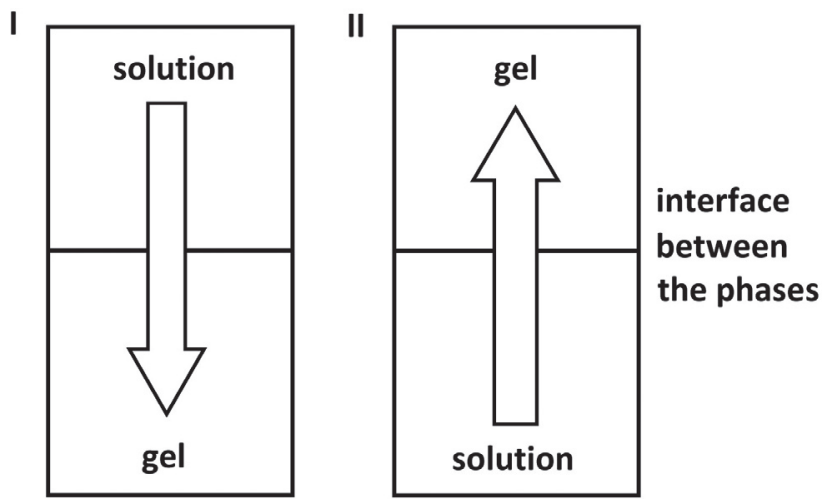

Figure 1. Gravitational configurations of the investigated gel systems.

\section{Results and Discussion}

Fig. 2 shows the results of fluorescence analysis of the structure of agarose gel of concentration of $0.5 \%$ and $1.5 \%$. Figs. $2 \mathrm{~A}$ and $2 \mathrm{E}$ show images of the gel plane with the highest values of fluorescence intensity, whereas Figs. $2 \mathrm{~B}$ and $2 \mathrm{~F}$ present appropriate 3-D plots of fluorescence intensity of agarose solution of concentration $0.5 \%$ and $1.5 \%$, respectively. For better illustration, the plots of fluorescence intensity along vertical and horizontal direction (white lines in Figs. 2A,B) are also presented (Figs. 2C, G and 2D,H).

The presented data indicate on higher fluorescence intensity for agarose gel of concentration $1.5 \%$ than $0.5 \%$. The average fluorescence intensity level and standard deviation for gel at concentration of $1.5 \%$ are equal $1610.05 \pm 69.51$ (vertical direction) and $1667.64 \pm 123.82$ (horizontal direction), whereas for gel of concentration of $0.5 \%$ these values are equal to $1131.17 \pm 95.67$ and $1091.74 \pm 90.87$. The level of acridine orange fluorescence is positively correlated with the agarose gel concentration. We suggest that above correlation might be associated with electrostatic interactions between fluorescence dye and galactoses that form helical fibres of agarose. The agarose gel at $1.5 \%$ concentration aggregate into supercoiled structure more effectively than gel at $0.5 \%$. We observed that the fluorescence of agarose stained by acridine orange is positively but not linearly correlated with gel concentration. The level of fluorescence of $1.5 \%$ agarose gel stained by fluorescence dye is 1.47 times higher than gel at 3 times lower concentration ( $0.5 \%)$. It means that the structure uniformity of the agarose gel at higher concentrations is not maintained. This is confirmed by visual analysis of the received images and plots. For the less concentrated gel one can see that the surface is uniform (Figs. 1AB), whereas for the gel of concentration $1.5 \%$ the structure is irregular (Figs. 1EF) with clearly visible spaces of different degrees of density (higher porosity). 

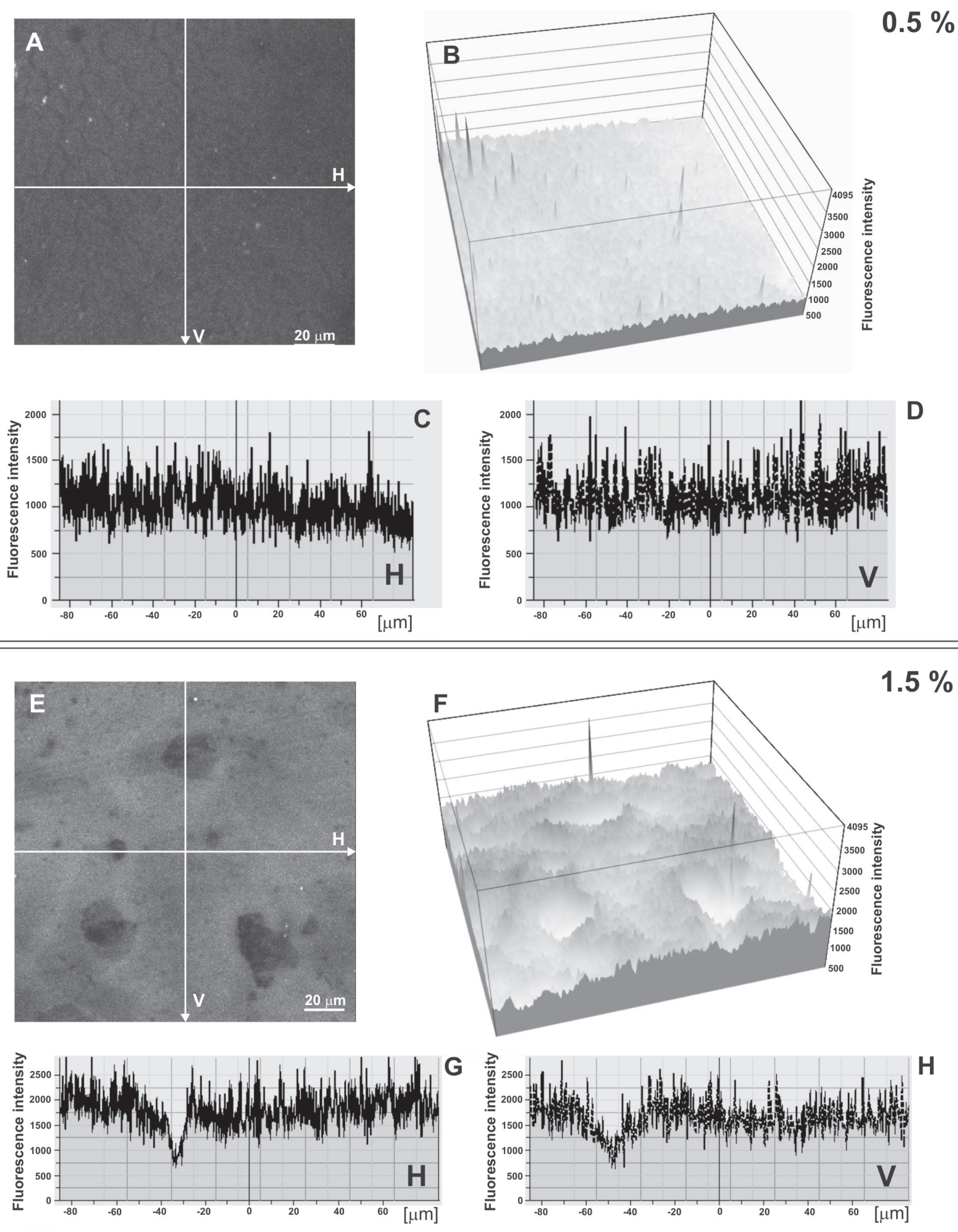

Figure 2. Microscopic images and fluorescence distribution obtained for the gel plane with the highest value of fluorescence intensity for agarose solutions of concentration $0.5 \%$ and $1.5 \%$ (detailed description in text). 
We concluded that the concentration of the medium as well as its structure should be taken into consideration for theoretical modeling of substance transport in gel structure.

In Figs. 3ABCD, the selected interferograms for both gravitational configurations of investigated gel system are shown. The bending of the interferometric fringes in the vicinity of the phases boundary indicates on sugar diffusion from aqueous solution into the agarose gel. In addition, we can find that the running of the fringes in areas outside the diffusion layers is not disturbed, which means no convection in both gravitational configurations of the system. Configuration II in the case of the use of water instead of the gel is stable at all times, whereas the configuration I is stable only when the concentration gradient is relatively small and the viscosity forces in solution balance the buoyant force. In such a state, the dimensionless parameter describing the relationship between the forces of buoyancy and viscous forces, i.e. the concentration Rayleigh number $R a_{\mathrm{c}}$ does not exceed a certain critical value. Concentration fluctuations and thus the density fluctuations are damped and in the system only diffusive transport of solute occurs. When the buoyant forces exceed the viscous forces ( $R a_{\mathrm{c}}$ exceeds a critical value), the transition of the system from the stable to unstable state occurs. In the system, besides the diffusive transport, addi- tionally convective transport of solute appears which results in the destruction of concentration boundary layers. The convection is a major factor hindering or even preventing quantitative analysis of the transport processes of substances in a variety of systems, especially in cases of high concentration gradients and substances with significant molar masses. The appearance of free gravity convection manifests itself in images by the noticeable perturbations of the interference fringes run. The obtained interferograms confirm the ability to strong damping of convective instabilities by the agarose gel. Both configurations I and II of the system in which this gel was used are gravitationally stable and in such a system we observe only diffusive transport of substances occurring according or against the force of gravity.

In previous work (Wąsik et al. 2010), the differential effect in the flow of glucose and sucrose as well as the time evolution of the concentration field in two configurations of the system were determined. The aim of the present study is a quantitative analysis of the fluxes $J s(t)$ of glucose and sucrose diffusing in agarose gel and the determination of the so-called gravitation polarization coefficient. In Fig. $4 \mathrm{AB}$, the time characteristics of $J_{\mathrm{s}}(t)$ for glucose obtained from Eq. (1) for both investigated configurations of the system are presented. These curves are typical for the diffusion process analyzed at the macroscopic level. In the initial
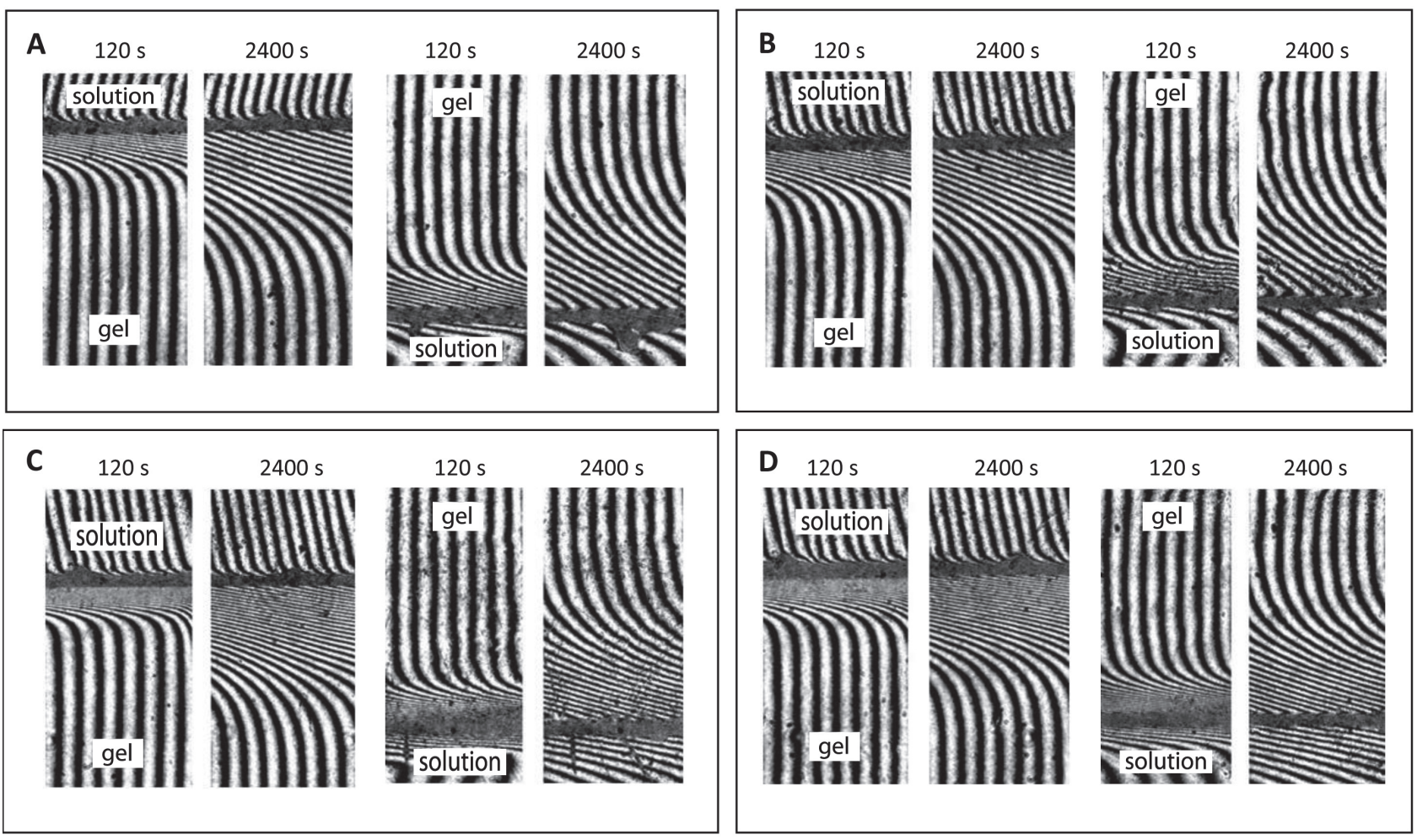

Figure 3. Interferograms for times $120 \mathrm{~s}$ and $2400 \mathrm{~s}$ obtained in configurations I and II of the gel system for glucose and $0.5 \%$ agarose (A), glucose and $3 \%$ agarose (B), sucrose and $0.5 \%$ agarose $(\mathbf{C})$, sucrose and $3 \%$ agarose (D). 
phase of the diffusion process we observe the rapid decrease of substance flux with increasing of concentration polarization. On the basis of these curves, we can determine the kinetics of glucose transport in agarose gel. The graphs show that the fluxes of glucose which diffuses in accordance with the force of gravity are significantly higher than those for the transport in the opposite direction. Furthermore, it can be seen that for the gel at concentration of $3 \%$ glucose flux values are smaller for all times than for a gel at concentration of $0.5 \%$. This allows to conclude - if the crowding of the hydrogel fibers is higher (higher concentration) then the amount of substance diffused into gel is lower.

Similar dependencies $J_{\mathrm{s}}(t)$ obtained for sucrose (Fig. $4 C D$ ) indicate that similarly as for glucose the diffusive transport of the substance is faster when the effect of fiber crowding in gel is lower. This means that more of the substance passes at given time through the phases boundary and the transport process is more efficient. Here the gravitational configuration of the system is also important, because for the transport occurring according to the gravity force it states higher flux values.

Comparing, in turn, pairs of Fig. $4 \mathrm{AB}$ and Fig. $4 \mathrm{CD}$ one can conclude that sucrose diffuses to the gel considerably less than glucose (in spite of identical starting concentrations). It is related to difference of their sizes and molecular weights. The molecule of sucrose (a disaccharide consisting of glucose and fructose) is larger than a molecule of glucose (a simple sugar), so it has limited mobility in the gel pores.

In order to quantify the influence of the gravitational configuration on the phenomenon of transport of substances in gel we introduce the gravitation polarization coefficient, which is expressed in the following form:

$$
p=\frac{J_{S I}-J_{S I I}}{J_{S I}+J_{S I I}}
$$

where: $J_{S I}$ is the flux of substance, which diffuses according to the gravity force, while $J_{\text {SII }}$ is flux of substance in case
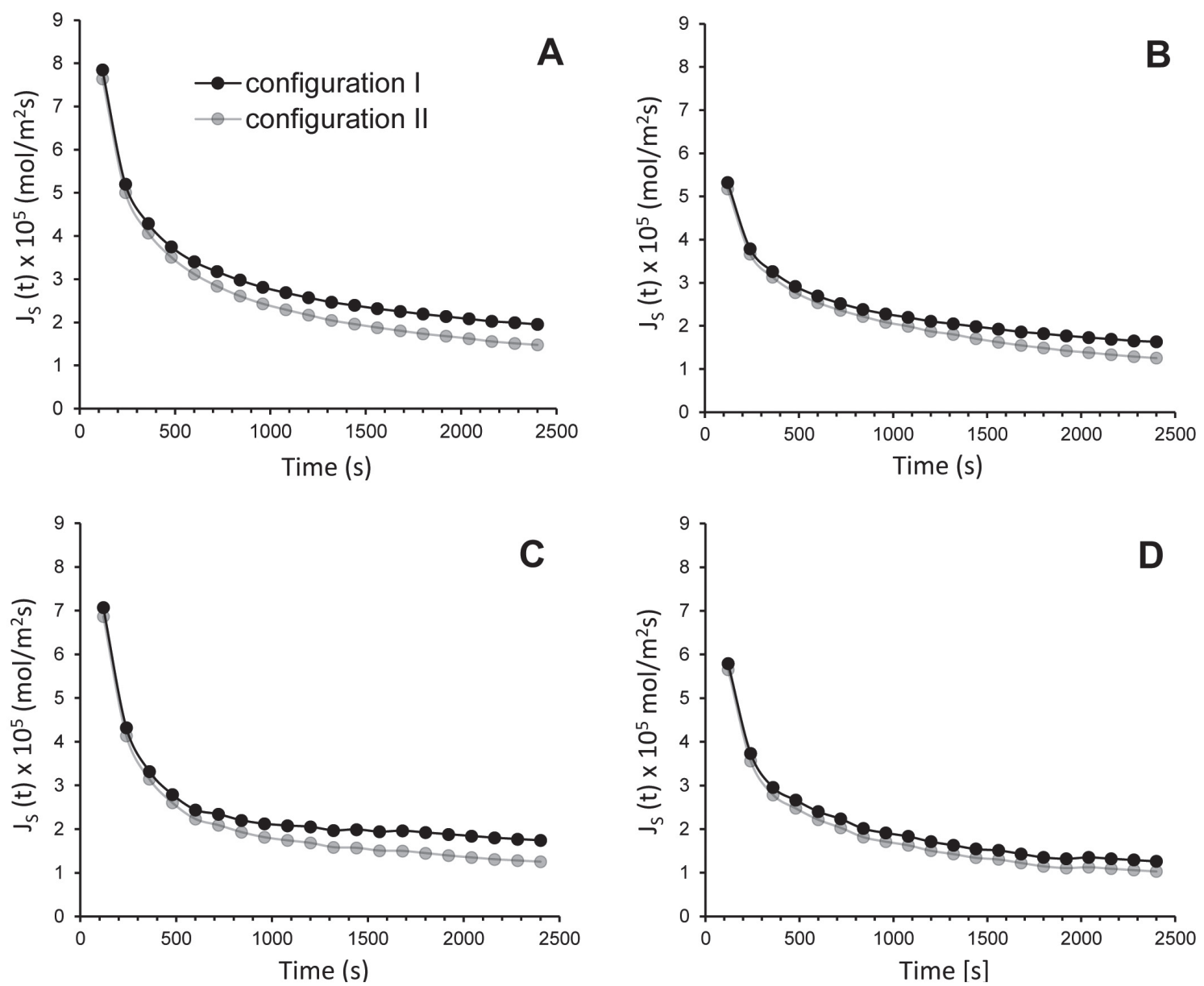

Figure 4. Time dependencies $J_{s}(t)$ obtained in configurations I and II of the gel system for glucose and $0.5 \%$ agarose (A), glucose and $3 \%$ agarose $(\mathbf{B})$, sucrose and $0.5 \%$ agarose $(\mathbf{C})$, sucrose and $3 \%$ agarose $(\mathbf{D})$. 

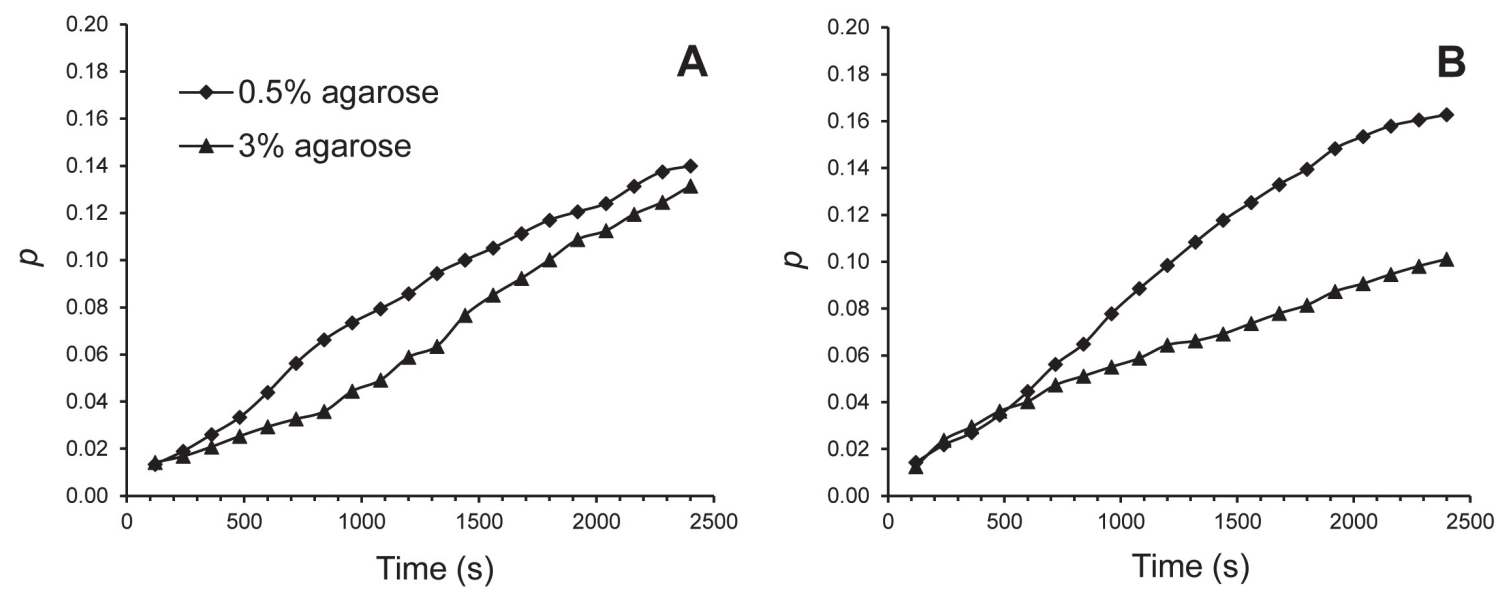

Figure 5. Time dependencies of the gravitational polarization coefficient (p) obtained for glucose (A) and sucrose (B).

of the diffusive transport in the opposite direction to the action of this force.

Fig. 5A illustrates the time dependence of the gravitation polarization coefficient for the systems with glucose diffusing in $0.5 \%$ and $3 \%$ agarose gel, whereas, Fig. $5 \mathrm{~B}$ illustrates the same relation to sucrose. All shown dependences indicate a significant increase of the gravitation polarization coefficient with time. This means that the difference between the fluxes (as well as between the amounts of the transported substance) for both gravitational configurations of the system is not constant, but also increases with time. Also, the values of this coefficient for the time range $(0-500 \mathrm{~s})$, both in the case of glucose and sucrose, appear to be the same for both the gel concentrations. For longer times it is observed that for both of these substances the value of gravitation polarization coefficient for less concentrated gel is higher. It is associated with higher "permeability" of the gels with lower concentrations due to their low degree of crosslinking which was confirmed earlier. The concentration of the gel regulates its porosity. If the concentration of agarose is lower, then crosslinking of the structure is less, which means that the pores (in which the substance diffuses) are larger. This observation leads to the conclusion that the gravitational effect should be particularly significant in the case of phases in which the substance diffuses easily.

In conclusion, interferometric investigations confirm the strong ability of agarose gel to damping of the convective instabilities. This gives the opportunity to study of diffusive transport of various substances in a variety gravitational configurations. The performed study showed significant differences in the diffusion fluxes values for glucose and sucrose diffusing into agarose gel according and opposite to the gravitational force.

Acknowledgments. This work was supported by a scientific grant from Jan Kochanowski University in Kielce, No. 612450.

\section{References}

Arabski M., Wąsik S., Dworecki K., Kaca W. (2007): Laser interferometric determination of ampicillin and colistin transfer through cellulose biomembrane in the presence of Proteus vulgaris O25 lipopolysaccharide. J. Membr. Sci. 299, 268-275

http://dx.doi.org/10.1016/j.memsci.2007.05.003

Arabski M., Davydova V. N., Wąsik S., Reunov A. V., Lapshina L. A., Yermak I. M., Kaca W. (2009a): Binding of lipopolysaccharide from Proteus vulgaris O25 (48/57) with chitosan. Carbohydr. Polym. 78, 481-487 http://dx.doi.org/10.1016/j.carbpol.2009.05.004

Arabski M., Wąsik S., Dworecki K., Kaca W. (2009b): Laser interferometric and cultivation methods for measurement of colistin/ampicilin and saponin interactions with smooth and rough of Proteus mirabilis lipopolysaccharides and cells. J. Microbiol. Meth. 77, 179-183 http://dx.doi.org/10.1016/j.mimet.2009.01.020

Axelsson A., Marucci M. (2008): The use of holographic interferometry and electron speckle pattern interferometry for diffusion measurement in biochemical and pharmaceutical engineering applications. Optic. Laser Eng. 46, 865-876 http://dx.doi.org/10.1016/j.optlaseng.2008.03.017

Barry P. H., Diamond J. M. (1984): Effects of unstirred layers on membrane phenomena. Physiol. Rev. 64, 763-872

Berry C. A., Verkman A. S. (1988): Osmotic gradient dependence of osmotic water permeability in rabbit proximal convoluted tubule. J. Membr. Biol. 105, 33-43 http://dx.doi.org/10.1007/BF01871104

Brandl F., Kastner F., Gschwind R. M., Blunk T., Teßmar J., Göpferich A. (2010): Hydrogel-based drug delivery systems: Comparison of drug diffusivity and release kinetics. J. Contr. Release 142, 221-228 http://dx.doi.org/10.1016/j.jconrel.2009.10.030

Claassen D. E., Spooner B. S. (1994): Impact of altered gravity on aspects of cell biology. Int. Rev. Cytol. 156, 301-373 http://dx.doi.org/10.1016/S0074-7696(08)62257-3 
Cogoli A., Gründer F. K. (1991): Gravity effects on single cells: techniques, findings and theory. Adv. Space Biol. Med. 1, $183-248$ http://dx.doi.org/10.1016/S1569-2574(08)60125-2

Cogoli A. (1993): The effect of hypogravity and hypergravity on cells on the immune system. J. Leukoc. Biol. 54, 259-268

Cogoli A., Cogoli-Greuter M. (1997): Activation and proliferation of lymfocytes and other mamalian cells in microgravity. Adv. Space Biol. Med. 6, 33-79 http://dx.doi.org/10.1016/S1569-2574(08)60077-5

Dworecki K., Ślęzak A., Drabik M., Ornal-Wąsik B., Wąsik S. (2006): Determination of the membrane permeability coefficient under concentration polarisation conditions. Desalination 198, 326-334 http://dx.doi.org/10.1016/j.desal.2006.03.518

Everitt C. T., Haydon D. A. (1969): Influence of diffusion layers during osmotic flow across bimolecular lipid membranes. J. Theor. Biol. 22, 9-19 http://dx.doi.org/10.1016/0022-5193(69)90076-9

Gasset G., Tixador R., Eche B., Lapchine L., Moatti N., Toorop P., Woldringh C. (1994): Growth and division of Escherichia coli under microgravity. Res. Microbiol. 145, 111-120 http://dx.doi.org/10.1016/0923-2508(94)90004-3

Griess G. A., Moreno E. T., Easom R. A., Server P. (1989): The sieving of spheres during agarose gel electrophoresis: quantition and modelling. Biopolymers 28, 1475-1484 http://dx.doi.org/10.1002/bip.360280811

Gustafsson N. O., Westrin B., Axelsson A., Zacchi G. (1993): Measurement of diffusion coefficients in gels using holographic laser interferometry. Biotechnol. Prog. 9, 436-441 http://dx.doi.org/10.1021/bp00022a011

Hatlan J. P., Lewis M. L., Roqnefeuil S. B., Chaput D., Carenave J. P., Schmitt D. A. (1998): Use of an adaptable cell culture kit for performing lymphocyte and monocyte cell culture in microgravity. J. Cell Biochem. 70, 252-267

http://dx.doi.org/10.1002/(SICI)1097-4644(19980801) 70:2<252::AID-JCB11>3.0.CO;2-P

Hoffman A. S. (2002): Hydrogels for biomedical applications. Adv. Drug Deliv. Rev. 54, 3-12 http://dx.doi.org/10.1016/S0169-409X(01)00239-3

Hughes-Fulford M. (1993): Review of the biological effects of weightlessness on the human endocrine system, Receptor 3, $145-154$

Karlsson D., Zacchi G., Axelsson A. (2002): Electronic speckle pattern interferometry: a tool for determining diffusion and partition coefficients for proteins in gels. Biotechnol. Prog. 18, 1423-1430 http://dx.doi.org/10.1021/bp0255659

Krylov A. V., Pohl P., Zeidel M. L., Hill W. G. (2001): Water permeability of asymmetric planar lipid bilayers: leaflets of different composition offer independent and additive resistances to permeation. J. Gen. Physiol. 118, 333-340 http://dx.doi.org/10.1085/jgp.118.4.333

Marucci M., Ragnarsson G., Axelsson A. (2006): Electronic speckle pattern interferometry: A novel non-invasive tool for studying drug transport rate through free films. J. Contr. Release 114, 369-380

http://dx.doi.org/10.1016/j.jconrel.2006.06.019
Marucci M., Pettersson S. G., Ragnarsson G., Axelsson A. (2007): Determination of a diffusion coefficient in a membrane by electronic speckle pattern interferometry: a new method and a temperature sensitivity study. J. Phys. D: Appl. Phys. 40, $2870-2880$ http://dx.doi.org/10.1088/0022-3727/40/9/031

Mattisson C., Nylander T., Axelsson A., Zacchi G. (1996): Diffusivity measurements using holographic laser interferometry in a cubic lipid-water phase. Chem. Phys. Lipids 84, 1-12 http://dx.doi.org/10.1016/S0009-3084(96)02604-7

Mattisson C., Roger P., Jönsson B., Axelsson A., Zacchi G. (2000): Diffusion of lysozyme in gels and liquids. A general approach for the determination of diffusion coefficients using holographic laser interferometry. J. Chrom. B, 743, 151-167

Mattisson C., Karlsson D., Pettersson S. G., Zacchi G., Axelsson A. (2001): Light deflection and convection in diffusion experiments using holographic interferometry. J. Phys. D: Appl. Phys. 34, 3088-3096 http://dx.doi.org/10.1088/0022-3727/34/20/314

Pedley T.J. and Fischbarg J. (1980): Unstirrd layer effects in osmotic water flow across gall-bladder epithelium. J. Membr. Biol. 54, 89-102 http://dx.doi.org/10.1007/BF01940563

Pedley T. J. (1983): Calculation of unstirred layer thickness in membrane transport experiments: a survey. Q Rev. Biophys. 16, 115-150 http://dx.doi.org/10.1017/S0033583500005060

Pedley T. J., Fischbarg J. (1978): The development of osmotic flow through an unstirred layer. J. Theoret. Biol. 70, 426-446 http://dx.doi.org/10.1016/0022-5193(78)90251-5

Pohl P., Saparov S. M., Antonenko Y. N. (1997): The effect of transmembrane osmotic flux on the ion concentration distribution in the immediate membrane vicinity measured by microelectrodes. Biophys. J. 72, 1711-1718 http://dx.doi.org/10.1016/S0006-3495(97)78817-9

Potma E.O., de Boeij W. P., Bosgraaf L., Roelofs J., van Haastert P. J. M., Wiersma D. A. (2001): Reduced protein diffusion rate by cytoskeleton in vegetative and polarized Dictyostelium cells, Biophys. J. 81, 2010-2019 http://dx.doi.org/10.1016/S0006-3495(01)75851-1

Roger P., Mattisson Ch., Axelsson A., Zacchi G. (2000): Use of holographic laser interferometry to study the diffusion of polymers in gels. Biotechnol. Bioeng. 69, 654-663

http://dx.doi.org/10.1002/1097-0290(20000920)69:6<654:: AID-BIT10>3.0.CO;2-N

Sato A., Nakajima T., Kumei Y., Hango T. and Ozawa K. (1992): Gravitational effects on mammalian cells. Physiologist 35, 43-46

Schatz A., Linke-Hommes A. (1989): Gravity and the membranesolution interface: theoretical investigations. Adv. Space Res. 9, 61-64 http://dx.doi.org/10.1016/0273-1177(89)90055-0

Schatz A., Reitstetter R., Briegleb W., Linke-Hommes A. (1992): Gravity effects on biological systems. Adv. Space Res. 12, 51-3 http://dx.doi.org/10.1016/0273-1177(92)90263-W

Tairbekov M. G., Gabova A. V., Gavrilova O. N. (1997a): Patterns in the growth and functioning of single-cell organism under conditions of altered gravitational force, Izv. Acad. Nauk. Ser. Biol. 3, 266-273 
Tairbekov M. G., Klimovitskii V. I., Oganov V. S. (1997b): The role of gravitational force in the evolution of living system (the biomedical and energy aspects). Izv. Acad. Nauk. Ser. Biol. 5, 517-530

Thomson A. B. R., Dietschy J. M. (1977): Derivation of the equations that describe the effects of unstirred water layers on the kinetic parameters of active transport processes in the intestine. J. Theor. Biol. 64, 277-294 http://dx.doi.org/10.1016/0022-5193(77)90357-5

Tosteson D. C. (1978): Transport across single biological membranes. In: Membrane Transport in Biology, vol. I. (Eds. G. Giebisch, D. C. Tosteson, H. H. Ussing), pp. 1-54, SpringerVerlag, Berlin

Vico L., Lafage-Proust M. M., Alexandre C. (1998): Effects of gravitational changes on the bone system in vitro and in vivo, Bone 22, 95-100
http://dx.doi.org/10.1016/S8756-3282(98)00017-9

Wąsik S., Arabski M., Dworecki K., Kaca W., Ślęzak A.: (2010) Influence of gravitational field on substance transport in gels. J. Membr. Sci. 365, 341-346

http://dx.doi.org/10.1016/j.memsci.2010.09.035

Westrin B. A., Axelsson A., Zacchi G. (1994): Diffusion measurement in gels. J. Contr. Release 30, 189-199 http://dx.doi.org/10.1016/0168-3659(94)90025-6

Zeuthen T. (1995): Molecular mechanisms for passive and active transport of water. Review. Int. Rev. Cytol. 160, 99-161 http://dx.doi.org/10.1016/S0074-7696(08)61554-5

Received: September 30, 2013

Final version accepted: May 19, 2014

First published online: July 17, 2014 